\title{
Making the Most of Site Visits
}

\section{Lindsey Anne Nelson, Purdue University, West Lafayette}

Lindsey Nelson is a Ph.D. student in Engineering Education at Purdue University. Her work centers upon helping engineering students connect meaningfully with global problems. She received her B.S. in Mechanical Engineering from Boston University and her M.A. in Poverty and Development from the Institute of Development Studies at the University of Sussex. Her research interests include engineering design for poverty alleviation, sustainable design, the public's understanding of engineering, poverty mitigation, student-centered engineering curricula, global participation, engineering design methodologies, real-world prototyping activities, and material culture. Her teaching interests include engineering design, authentic assessment, student advising, and K-12 outreach. Nelson has worked with elementary, middle school, high school, and undergraduate students in formal and informal settings. She strives to develop professionally as a teacher, implementing best practices informed by rigorous research. 


\section{Making the Most of Site Visits}

Using a service-learning pedagogy requires that engineering educators build connections with the community. ${ }^{1,2}$ However, these connections vary in quality. For example, engineering educators could create transactional agreements where community organizations accept student projects or engineering educators could cultivate long-standing partnerships where engineering students expand their design knowledge working alongside of various community stakeholders. ${ }^{3}$ Additionally, engineering students enter into a service-learning pedagogical experience with their own perceptions of working with community organizations and their own expectations of what they will learn and do during the course. ${ }^{4}$ When students work with local community partners, educators using service-learning pedagogies frequently expect students to perform site visits. ${ }^{5}$ If the community partner has good interactions with students, then the community partner may be more likely to continue the relationship. Conversely, bad student-community interactions may undercut efforts of engineering faculty trying to cultivate long-standing partnerships with specific community organizations. Since the bulk of interaction between students and community organizations may happen during site visits, engineering educators should understand how students' initial ideas about community partners shape how engineering students engage with community organizations.

The nature of the students' task influences how students might engage with community partners. Engineers typically find benefit in consulting with the client at key stages in the design process, especially when defining the problem for the engineering team and when evaluating prospective ideas. ${ }^{6}$ Engineers operating with human-centered design methods should take time to discern needs of various stakeholders in order to define good engineering design problems. ${ }^{4}$ The purpose of this paper is to discuss how engineering students responded to a problem-finding task when these students were expected to find evidence of a design challenge during a site visit to a community organization. I will discuss the targeted student population, detail the design of a learning experience that matched key features of service-learning pedagogy, reflect on the experience of leading the learning experience with students, and analyze the deliverables prepared by students during the learning episode. The goal of this paper is to open a conversation with other engineering educators using service-learning pedagogies about how to prepare students to make the most of site visits to community partners.

\section{The Students}

I intentionally designed this learning experience for students enrolled in a service-learning program at a major university in the Midwest. Students participate in multidisciplinary design teams that have long-term commitments to working with specific community partners. Each team organizes itself so as to give students project leadership experience. Typical leadership roles include team leader, project leader, financial officer, web master, and community partner liaison. Students can participate during the program at any point during their college experience; many students who participate in the program use the academic credits as technical electives within their engineering disciplines. To receive academic credit, each student is expected to make active contributions on a design project and attend a certain number of lecture credits. The program provides students with a wide selection of learning experiences to receive lecture credits that include everything from hands-on machining lessons to improve soldering abilities to lectures on the design process to attending design reviews of other project teams. Students 
register to attend specific learning experiences in order to achieve their requisite number of lecture credits.

I advertised the Making the Most of Site Visits learning experience within the program, capping enrollment at forty students. I specified that students serving as community partner liaisons may find the learning experience to be especially relevant. 32 students from 18 project groups attended the Making the Most of Site Visits skills session. These students include undergraduates at all levels that major in many different disciplines. I used reflective worksheets distributed throughout the session to take attendance so I could verify which students attended.

\section{The Learning Experience}

The learning experience featured several elements of service-learning pedagogy. ${ }^{1}$ Pedagogically, advocates for service learning argue that service-learning affords students a real-world context for learning academic content experientially. Advocates for service-learning believe that students will be more motivated to complete tasks if these tasks have meaning in the student's community. According to Zlotkowski, ${ }^{1}$ for a learning experience to be a valid service-learning experience, "it must evidence

- explicit, accessible learning objectives,

- community-sponsored activities that promote civic responsibility,

- $\quad$ structured, multi-layered reflection opportunities, and

- reciprocity between the academic and community partners with regard to the resources, needs, objectives, and priorities that define the partnership" (43).

Additionally, the learning experience needed to have relevance for students attached to many different design teams. All student teams have different histories with their community partners and have design projects at differing development levels. Moreover, some student teams have international community partners. The learning objectives of the Making the Most of Site Visits learning experience had to meet the needs of a diverse group of students.

The service-learning program focuses on teaching students human-centered design. All new students to the program attend orientation lectures that introduce the students to core components of human-centered design. Many instructors working with students in the service-learning program stress the importance of identifying stakeholders. Earlier in the semester, students had an opportunity to receive lecture credits by attending a workshop on understanding stakeholders and the social context. Therefore, I designed a lesson plan targeting five learning objectives:

1. Assess needs found in a local community organization

2. Evaluate which problems are good design problems

3. Articulate core considerations of working with community organizations

4. Identify assumptions about which stakeholders should be consulted

5. Revise team processes through reflectively considering alternate processes.

In addition to identifying appropriate learning objectives, instructors incorporating a servicelearning pedagogy should consider ways to involve students in their community with authentic tasks. ${ }^{1,5}$ Therefore, I included a site visit to two of the campus libraries where students were expected to identify three engineering design problems located in the campus libraries. I chose the campus libraries for several reasons. The service-learning program has worked with different academic units on campus to improve facilities; one project team began with a desire to make the 
campus more environmentally sustainable. Additionally, every participant in the learning experience had access to the campus libraries because all participants were enrolled as students in the university. During the learning experience, I discussed with the students the importance of negotiating access to community organizations. I shared what steps I completed to negotiate sensible access to the two university libraries I selected. Lastly, the campus libraries directly engage a complex network of stakeholders such as professional librarians, full-time employees, work-study students, graduate students in many different academic disciplines, undergraduate students in many different academic disciplines, and members of the general public. Some design problems might also involve identifying other stakeholders like university administrators, politicians representing the interests of a public university, people using the libraries during special events, and philanthropists who fund public education. The complex stakeholder network of the campus libraries mirrors the stakeholder network of other community organizations. ${ }^{7}$

Lastly, instructors using a service-learning pedagogy should provide students with opportunities for reflection. Building from Schon, ${ }^{8}$ reflective practice follows two main modes of reflection-inaction and reflection-on-action. To structure student reflections, I provided four reflection guides. These guides asked students to 1) plan their information gathering strategy in the library, 2) identify evidence of three design problems in the library, 3) reflect on the effectiveness of their planned information gathering strategy, and 4) reflect on the session as a whole. The first two guides used reflection-in-action while the last two guides used reflection-on-action. I have included all four reflection guides as an appendix.

The overall learning experience lasted two hours. The sequence and timing of learning activities is below:

- 5 minutes - Welcome and Introductions

- 10 minutes - Overview of Site Visits

- 15 minutes - Planning library site visit with the $1^{\text {st }}$ reflection guide

- $\quad 30$ minutes - Library site visit with the $2^{\text {nd }}$ reflection guide

- 25 minutes - In-team reflections with the $3^{\text {rd }}$ reflection guide

- 25 minutes - Facilitated large-group discussion

- 10 minutes - Conclusion with the $4^{\text {th }}$ reflection guide

\section{Reflections on the Immediate Experience}

Instructors should be willing to modify learning objectives to meet student needs. ${ }^{9,}{ }^{10}$ In the case of the Making the Most of Site Visits learning experience, students entered the learning experience with a low opinion of site visits. After introducing the concept of site visits, I asked students what strategies they might use to gather information from a community partner. I anticipated students reflecting on the site visit context and proposing methods like walking around the site, observing different people at the site, performing interviews with diverse stakeholders, sketching maps of the floor plan, and directly testing how the community partner ensures that people can access provided services. Instead, students discussed informationgathering strategies that could be done at a distance. The first three strategies named were visiting the community partner's website, performing library research, and talking with team members who had previously visited the organization. Students then suggested two ambiguous strategies: 1) take notes and 2) take pictures. I then tried to press students with questions about what would go in their notes and how they would know that pictures might be useful. Students 
struggled to articulate how they would know what details to capture in notes and pictures until I suggested the word "observation." This orienting discussion indicated that students might have a low opinion of site visits as a useful information gathering discussion or have technocratic conceptions of engineering design.

The next learning activity asked students to plan their information gathering strategy for their site visit to one of the campus libraries. As I rotated around different teams, I noticed that several student teams began by brainstorming problems they had previously encountered in the library. I redirected students towards the planning task by working with their individual teams and by making an announcement to the entire group. These immediate observations supported other researchers' findings that engineering students will approach human-centered design by designing for themselves. ${ }^{11-14}$ When a student team had completed their information-gathering plan, I dismissed that team to their assigned library for a thirty-minute site visit. Although I had anticipated that student teams would need the entire thirty minutes for the site visit, the first student team returned twelve minutes after being dismissed to the library.

These initial observations shifted my learning objectives in an effort to encourage student teams to see value in conducting site visits. The learning objectives shifted to the following:

1. Assess needs found in a local community organization

2. Evaluate which problems are good design problems

3. Articulate core considerations of working with community organizations

4. Identify Reflect on assumptions about which stakeholders should be consulted

5. Revise team processes through reflectively considering alternate processes. Identify how student teams can work in concert with the service-learning program office to best serve community partners.

I lead a synthesis discussion with the students to explore what design problems student teams found, how to decide if design problems were good problems for future projects affiliated with the service-learning program, and why students should look broadly for design problems when conducting a site visit. The discussion revealed at least two viable design challenges that matched well to the service-learning program's capabilities. The first project involved improving the acoustics of a quiet study area; the second project involved conducting an energy audit on one campus library to determine the power needs of an appropriate study environment. The discussion focused on the importance of walking through the entire site, talking with many different stakeholders, and looking for synergistic evidence from different site visit teams. Students asked many questions about conducting interviews during site visits because students realized survey methods could be intrusive or limited by convenience sampling. Several students found the learning experience useful and asked for follow-up programming related to site visits.

\section{Making Sense of Student Deliverables}

Students completed four deliverables during the Making the Most of Site Visits learning experience. Each student team collaborated to plan an information gathering strategy before their site visit, listed three engineering design problems with supporting evidence gathered during the site visit, and reflected on the efficacy of their team process. Additionally, every student completed an individual reflection at the conclusion of the learning experience. I collected all 
four reflection guides from each student to verify attendance. These reflection guides gave students opportunities to reflect-in-action and to reflect-on-action.

Students demonstrated divergent understandings of the design process throughout the learning experience. These understandings include views previously articulated by other researchers. ${ }^{4}$ Even in the two-hour Making the Most of Site Visits workshop, I saw evidence of students defining design as technology-centered, a linear process requiring information, a process informed by user's needs, and a process shaped by the user's perspective. While students frequently had a dominant definition of design, some student teams used different tools to consider design from multiple perspectives. Given the relatively limited scope of the Making the Most of Site Visits learning experience and the fact that many engineers see value in asking users about their experiences to successfully complete need-finding tasks, ${ }^{15-17}$ readers should understand the analysis below as preliminary analysis. Nevertheless, I think these observations provide needed insight into how engineering students approach design tasks and can further dialogue amongst engineering educators about how to best design learning experiences for students working with community organizations. In the following sections, I detail how students defined design, what tools these students used to gather information about site visits, and how engineering educators using service-learning pedagogies might appropriately scaffold design learning for students with each definition.

\section{Design as technology-centered}

Many students approached design as a technology-centered activity. These students displayed a pattern of beginning with their own knowledge, collecting data through objective measuring techniques, and maintaining their originally developed plan. Students who viewed design as technology-centered tended to jump immediately to identifying problems and solutions. Several of these students included prospective solutions on the sheet that asked students to identify engineering design problems and provide evidence the problem existed. Additionally, these students described the time effectiveness of their information gathering strategy when asked about the success of their information gathering strategy.

Although technology-centered strategies can improve time effectiveness, students should be encouraged to reflect on the costs and benefits of specific strategies. Nearly every student who attended the Making the Most of Site Visits learning experience said they captured a picture to provide evidence of a particular engineering design challenge. One student expressed frustration the team forgot a camera because this student believed "cameras offer better evidence." Engineering design educators may benefit from helping students learn to critically evaluate pictorial evidence. Moreover, the high value students place on being efficient may undermine other learning objectives. For example, one student team reflected that having a community partner provide a tour guide would have improved their information gathering strategy. This suggestion raises several issues related to expectations students and faculty may have of community partners. First, students may approach a community partner expecting a high degree of preferential treatment. ${ }^{18}$ Second, community partners may experience significant costs to orient students properly if students expect a full orientation done by the community partner before doing work. ${ }^{3,19}$ Third, students relying on tour guides may miss several opportunities to collect candid observations related to problems within the organization. ${ }^{20}$ Students taking a technology-centered approach to design may view themselves as the most important stakeholder 
in the process. ${ }^{4}$ These students may dismiss the site visit as something only useful to fulfill a course requirement or center knowledge within themselves. One student explained that "all needs became apparent upon reflection" because the student could connect various hunches about what may be a problem to observations. Finally, students taking a technology-centered view of design may express a desire to learn about less personal ways of working with community partners. One student at the close of the session asked for a follow-up session on "dealing with corporate partners (email, etc)."

Engineering educators working with service-learning pedagogies should be aware that simply having students develop designs for a community partner does not mean students adopt a respectful approach when working with community organizations. Engineering students likely actively construct their view of design while taking design classes. ${ }^{21-23}$ Therefore, engineering educators should consider encouraging students to reflect on respectful behavior, incorporating role plays that highlight how community partners might perceive students, challenging problems or solutions immediately posed by students, and exhorting students towards claims clearly supported by evidence.

\section{Design as a linear process requiring information}

Several students viewed design as a linear process requiring information. These students considered how information might be gathered during the site visit, frequently addressing the need to talk to users. These students placed interviewing users in a sequence of activities. Some teams used interviews as a way to verify what the team had already observed; other teams began quickly by conducting interviews before moving onto other strategies. Oftentimes, these student teams did not specify what information they sought from users. Occasionally, these students crafted a short survey or indicated openness to hearing what users might want.

Engineering design educators working with students seeing design as a linear process requiring information might do well to encourage students to gather information at many different steps in the design process. Students relying on a strongly linear process frequently displayed behaviors consonant with technology-centered design. One student asked for additional guidance about what to do when community partners resist implementing team suggestions. If users only have input at the start of the linear design process, then students may unintentionally alienate community partners by forcing community organizations to adopt solutions. ${ }^{19}$ Students and engineering educations should be mindful of this kind of presumption, especially if student teams pose solutions quickly.

Design as a process informed by user's needs

Several students showed evidence of believing that design is a process informed by user's needs. These students placed a high value on multiple approaches to gathering information as well as many different kinds of evidence. During the library site visit, these students observed the library environment, interviewed librarians and students using the library, observed different users in the library, and engaged in forms of participant observation. Students brainstormed questions in advance to be able to conduct quick interviews. Some student teams modified their data collection plan to be more respectful of users. One student team reported they decided not to interview students because the team did not want to disrupt people who were studying. Students seeing design as a process informed by user's needs also framed their evidence in terms of other 
user's behaviors. For instance, one student reported a problem with mobile phone reception. This student noted that students would congregate by the door or walk upstairs to check their phones because these students could not make a call to find their study group. While the student framed the engineering design problem as principally technology-driven, the student had notes to support developing solutions for users needing to locate their study group.

A significant proportion of students saw value in trying to use the library. However, several students approached user-questions from their own embodied experience rather than observing other users. In the case of mobile phone reception, other students thought mobile phone reception would be a problem before they visited the library. When in the library, these students looked at their own phone and reported the reception on the different cell phone networks that team members used. These students did not report why library users would need mobile phone reception. Students relying on their own experience exclusively had unclear evidence. Another team attempted to locate a book in the library. The students wrote a call number on their sheet, indicating they looked for a title in the library catalogue, and reported they could not find what they were looking for. These surface explanations lack utility for an engineering design team who would need to visit again to pinpoint likely sources of the locating resources problem.

Engineering educators encouraging students to consider user's needs during the design process may consider leading more structured planning exercises. Students with more linear design processes may plan to use one kind of evidence. Providing students with a list of potential information gathering strategies and encouraging students to find multiple corroborating pieces of evidence may provide more guidance to students. Additionally, needing to look for corroborating pieces of evidence may help students focus more on making high-quality observations rather than finishing quickly. Students who viewed design as a process informed by user's needs highlighted observations of other people rather than focusing exclusively on their own experience. Engineering educators could challenge students with exercises about making good user-centered observations to help students see beyond their own experience.

Design as a process shaped by the user's perspective

While no students took an approach indicating the student thought design is a process shaped by the user's perspective, several students used tools or made statements that could be indicative of taking the user's perspective. Many students used information-gathering strategies that incorporated them using the library. When asked about the efficacy of information-gathering strategies, one student noted, "Observing was the most successful. As students ourselves, I thought we could understand why students were doing what they were doing." Occasionally, students attempted to describe why particular users valued specific features of the library. Some students started the exercise open to suggestions from users, indicating a willingness to learn from users. Other students thought that their partner brought a valuable perspective to completing the site visit tasks.

Following the two-hour Making the Most of Site Visits learning experience, some students displayed increased willingness to see design as a process shaped by the user's perspective. We talked at length during the synthesis discussion about the challenges of incorporating the user's perspective into the design process. A student had asked a question about how to not bother students who were in the library to study. The discussion spanned many topics including 
potential bias of sampling strategies, the need to identify questions in advance of conducting interviews, the limited nature of a single site visit, and the difficulty in ensuring users understand the designer's questions. Several students expressed a desire for more learning experiences on research methods, effective communication, and relating to users.

Engineering educators using service-learning pedagogies should challenge students to recognize multiple perspectives. One student commented that she learned about the "need to come from many angles when doing a site visit. Users are \#1!" Additionally, engineering students would do well to remember they have limited knowledge. Even students who took a technology-centered view of design acknowledged that observations helped them see things they failed to anticipate. Lastly, engineering educators using service-learning pedagogies should appreciate the need to respond to students with just-in-time instruction. Because service learning engages students in experiential learning, students will likely perceive additional learning needs in the middle of learning experiences.

\section{Implications}

Although the Making the Most of Site Visits learning experience lasted for two hours, observations made of students in this learning experience have implications for engineering educators working with service-learning pedagogy. The Making the Most of Site Visits learning experience highlights that even short-term learning experiences can use a service-learning pedagogy. This learning experience used service-learning pedagogies as this communitycentered learning experience had specific academic learning objectives. By sharing the studentfound design problems with the service-learning program office, the learning experience has elements of community reciprocity. Analyzing student reflections highlights the importance of actually completing a site visit because several students focused their reflections on their visit to the library. Different students bring different assumptions about community partners.

Engineering educators using service-learning pedagogies may benefit from providing students with more structured planning exercises stressing the need for multiple perspectives and corroborating evidence. Students may benefit from specific learning experiences that incorporate many layers of reflective activities so as to reveal students' initial assumptions about site visits and the nature of working with community organizations.

While the students' reflections provided evidence of immediate learning, the students returned to diverse project contexts. Students participate in the program to learn more about engineering design and frequently describe their program participation in terms of their design projects. Because visiting community partners occurs outside of class time, many students focus on making progress on the project. The broader service-learning program continues to engage students in user-centered design, offering multiple workshops about working with community organizations and exploring new summer course offerings sited at community organizations. The Making the Most of Site Visits learning experience suggests that conceiving of design as a process shaped by the user's perspective requires the students to change their perspectives of design. This perspective shift likely happens gradually as students gain more experience with community organizations. 


\section{References}

1. Zlotkowski E. The Case for Service Learning. In: McIlrath L, MLabhrainn IM, eds. Higher Education and Civic Engagement: International Perspectives. Aldershot, England: Ashgate; 2007:37-54.

2. Coyle EJ, Jamieson LH, Oakes WC. EPICS: Engineering projects in community service. International Journal of Engineering Education. 2005;21(1):139-150.

3. Dorado S, Giles DE. Service-learning partnerships: Paths of engagement. Michigan Journal of Community Service Learning 2004;11(1):25-37.

4. Zoltowski CB, Oakes WC, Cardella ME. Students' Ways of Experiencing Human-Centered Design. Journal of Engineering Education. 2012;101(1):28-59.

5. Eyler J, Giles DE. Where's the Learning in Service-Learning? San Fransciso, CA: Jossey-Bass; 1999.

6. Paton B, Dorst K. Briefing and reframing: A situated practice. Design Studies. 2011;32(6):573-587.

7. Nolan R. Development Anthropology: Encounters in the Real World. Boulder, CO: Westview Press; 2002.

8. $\quad$ Schon D. Educating the Reflective Practitioner. San Fransciso, CA: Jossey-Bass; 1987.

9. Jarvis P. Towards a comprehensive theory of human learning. Vol 1. New York: Routledge; 2006.

10. Kolb DA. Experiential Learning: Experience as the Source of Learning and Development. Englewood Cliffs, NJ: Prentice-Hall; 1984.

11. Cardella ME, Zoltowski CB, Oakes WC. Developing human-centered design practices and perspectives through service-learning. In: Baillie C, Pawley AL, Riley D, eds. Engineering and Social Justice: In the University and Beyond. West Lafayette, IN: Purdue University Press; 2012:11-30.

12. Friess E. The Sword of Data: Does Human-Centered Design Fulfill Its Rhetorical Responsibility? Design Issues. 2010;25(3):40-50.

13. Steen M. Human-Centered Design as a Fragile Encounter. Design Issues. 2012;28(1):72-80.

14. Terpenny JP, Goff RM, Lohani VK, Mullin J, Lo J. Preparing Globally and Socially-Conscious Engineers: International and Human-Centred Design Projects and Activities in the First Year. International Journal of Engineering Education. 2008;24(2):409-419.

15. van de Poel I, van Gorp AC. The need for ethical reflection in engineering design: The relevance of type of design and design hierarchy. Science, Technology, and Human Values. 2006;31(3):333-360.

16. Garrety K, Badham R. User-Centered Design and the Normative Politics of Technology. Science, Technology, and Human Values. 2004;29(2):191-212.

17. Oudshoorn N, Pinch T. Introduction: How Users and Non-Users Matter. In: Oudshoorn N, Pink D, eds. How Users Matter: The Co-Construction of Users and Technology. Cambridge, MA: MIT Press; 2003:128.

18. Chambers R. Whose Reality Counts? Putting the First Last. Warwickshire, England: ITDG; 1997.

19. Hickey S, Mohan G. Towards participation as transformation: critical themes and challenges. In: Hickey S, Mohan G, eds. Participation: from tyranny to transformation? Exploring new approaches to participation in development. London: Zed Books; 2004:3-24.

20. Chambers R. Rural Development: Putting the Last First. London: Longman; 1983.

21. Dym CL, Agogino A, Eris O, Frey DD, Leifer L. Engineering design thinking, teaching, and learning. Journal of Engineering Education. 2005;94(1):103-120.

22. Sheppard SD, Macatangay K, Colby A, Sullivan WM. Educating Engineers: Designing for the Future of the Field. Stanford, CA: Jossey-Bass; 2009.

23. Strickfaden M, Heylighen A. Scrutinizing design educators' perceptions of the design process. AIEDAM. 2010;24(3):357-366. 


\section{Appendix A: Reflection Guides}

\section{Planning Your Site Visit}

To work effectively in communities, engineers often have to gather information quickly and systematically. Information can come from a variety of places: informal observations, touring the site, walking around, talking to people at the site, the engineer's personal knowledge of the site, comparing the site with similar sites, use surveys, and conducting formal research.

Your challenge is to identify what engineering design problems exist within <removed for blind review> libraries to help them better embody their commitment to "Access. Knowledge. Success." You will have up to 30 minutes where you will be able to go into a particular University library. Before you leave the room, take 15 minutes to plan your information gathering strategy as a team. You may use the back of this page as well. 


\section{In the Library}

Please use the space on this page to document engineering design problems found in the library. You should include evidence of how you know these problems exist within the specific library you visited.

Engineering Design Problem:

Evidence:

Engineering Design Problem:

Evidence:

Engineering Design Problem:

Evidence: 


\section{Information Gathering Process Review}

After coming back from the library, please answer the following questions as a team.

How effective was your planned strategy for finding engineering design challenges in the library? Explain your reasoning.

What aspects of your planned strategy were successful? Why do you think these strategies were successful?

What aspects of your planned strategy changed when you left the room? Why did your team make these shifts?

How did you decide that a problem was an engineering design problem?

Please prepare a picture of your team's information gathering process to post in the process gallery. 


\section{Making the Most of Site Visits}

After thinking through the different conversations we have had as a whole group, please respond to the following questions individually.

What did you learn during this workshop?

How did you learn these things?

Why is what you learned important?

How could this learning be applied when visiting your own community partner? 